\title{
Development of Electric and Chemical Microthrusters
}

\author{
M. Tajmar ${ }^{1,2}$ and C. A. Scharlemann ${ }^{2}$ \\ ${ }^{1}$ Department of Aerospace Engineering, KAIST, Daejeon 305-701, Republic of Korea \\ ${ }^{2}$ Aerospace Engineering Department, University of Applied Sciences at Wiener Neustadt, 2700 Wiener Neustadt, Austria
}

Correspondence should be addressed to M. Tajmar, martin.tajmar@kaist.ac.kr

Received 23 November 2010; Revised 20 February 2011; Accepted 19 March 2011

Academic Editor: Ikkoh Funaki

Copyright (C) 2011 M. Tajmar and C. A. Scharlemann. This is an open access article distributed under the Creative Commons Attribution License, which permits unrestricted use, distribution, and reproduction in any medium, provided the original work is properly cited.

The increasing application of microsatellites (from $10 \mathrm{~kg}$ up to $100 \mathrm{~kg}$ ) as well as CubeSats for a rising number of various missions demands the development of miniaturized propulsion systems. Fotec and The University of Applied Sciences at Wiener Neustadt is developing a number of micropropulsion technologies including both electric and chemical thrusters targeting high performance at small scales. Our electric propulsion developments include a series of FEEP (field emission electric propulsion) thrusters, of which the thrust ranges from $\mu \mathrm{N}$ to $\mathrm{mN}$ level. The thrusters are highly integrated into clusters of indium liquid-metal-ion sources that can provide ultralow thrust noise and long-term stability. We are also developing a micro PPT thruster that enables pointing capabilities for CubeSats. For chemical thrusters, we are developing novel micromonopropellant thrusters with several hundred $\mathrm{mN}$ as well as a $1-3 \mathrm{~N}$ bipropellant microrocket engine using green propellants and high specific impulse performance. This paper will give an overview of our micropropulsion developments at Fotec, highlighting performance as well as possible applications.

\section{Introduction}

The Aerospace Engineering Department at Fotec, the research company from The University of Applied Sciences at Wiener Neustadt in Austria (previously Space Propulsion and Advanced Concepts Department at the Austrian Institute of Technology) has a long history in developing liquidmetal-ion-sources (LMISs) for space applications [1]. The first test of an LMIS under microgravity conditions in space was performed during the AUSTROMIR mission in 1991. A number of scientific instruments followed, including the application of the ion source for active spacecraft potential control of satellites (ASPOC) as well as for a secondary ion mass spectrometer. To date, more than $16,500 \mathrm{~h}$ were accumulated on various spacecraft (see Table 1).

Since the late 1990s, our department focused on space propulsion applications, using the space-proven LMIS designs for field-emission-electric propulsion (FEEP) thrusters enabling ultra-precise attitude and orbit control required for highly demanding drag compensation [2, 3]. Over the last 5 years, our activities expanded in a number of other micropropulsion areas such as $\mu \mathrm{PPT}$ thrusters for CubeSats or chemical micropropulsion including the development of micro-monopropellant and bipropellant thrusters using green propellants.

This paper will give an overview of our developments. Key performance specifications of all micropropulsion systems under development are listed in Figure 1 and Table 2.

\section{Electric Micropropulsion}

2.1. Indium FEEP Thrusters. A Liquid-Metal-Ion Source (LMIS) is the core element of a Field-Emission-Electric Propulsion (FEEP) thruster. In order to provide an extremely accurate attitude and orbit control of satellites during the entire duration of the mission, such thrusters need to provide a thrust level of several tens of $\mu \mathrm{N}$ up to $100 \mu \mathrm{N}$ for several years of continuous operation. Translated into requirements for a LMIS, such ion sources need to provide up to $1 \mathrm{~mA}$ of current for about $20,000 \mathrm{~h}$ of operation in a maintenancefree environment. Some missions even require several $\mathrm{mN}$ of thrust (several tens of $\mathrm{mA}$ ) in order to move the satellite formation to a different orientation in addition to the usual drag-free compensation duty. 
TABLE 1: Space experience of indium LMIS (up to September 2009).

\begin{tabular}{|c|c|c|c|c|}
\hline Experiment & Function & Spacecraft & Na. of LMIS & Operation time \\
\hline LOGION & Test of LMIS in $\mu$-gravity & MIR & 1 & $24 \mathrm{~h}(1991)$ \\
\hline MIGMAS/A & Mass spectrometer & MIR & 1 & 120 h (1991-1994) \\
\hline EFE-IE & S/C potential control & GEOTAIL & 8 & 600 h (1992-) \\
\hline PCD & S/C potential control & EQUATOR-S & 8 & $250 \mathrm{~h}(1998)$ \\
\hline ASPOC & S/C potential control & CLUSTER & 32 & $\begin{array}{c}\text { Ariane } 5 \text { launch failure } 1996 \text { still } \\
\text { operational after crash }\end{array}$ \\
\hline ASPOC-II & S/C potential control & CLUSTER-II & 32 & $6516(2000-)$ \\
\hline COSIMA & Mass spectrometer & ROSETTA & 2 & Launched 2004 (tested in space) \\
\hline ASPOC/DSP & S/C potential control & DoubleStar & 4 & 8979 h $(2004-)$ \\
\hline
\end{tabular}

TABLE 2: Summary of micropropulsion key performance parameters.

\begin{tabular}{|c|c|c|c|c|c|}
\hline & \multicolumn{3}{|c|}{ Electric micropropulsion } & \multicolumn{2}{|c|}{ Chemical micropropulsion } \\
\hline & Single FEEP & $\mathrm{mN}$-FEEP & $\mu \mathrm{PPT}$ & Bipropellant & Monopropellant \\
\hline \multirow{2}{*}{ Size $(\mathrm{cm})$} & $\varnothing \sim 5 \mathrm{~cm}$ & $\varnothing \sim 10 \mathrm{~cm}$ & \multirow{2}{*}{$\sim 0.5 \times 0.7 \times 3.0 \mathrm{~mm}$} & $\varnothing \sim 3 \mathrm{~cm}$ & $\varnothing \sim 2.5 \mathrm{~cm}$ \\
\hline & $L \sim 10 \mathrm{~cm}$ & $L \sim 10 \mathrm{~cm}$ & & $L \sim 7 \mathrm{~cm}$ & $L \sim 5 \mathrm{~cm}$ \\
\hline Mass (kg) & $\begin{array}{c}80 \mathrm{~g} \text { thrusters }+ \\
700 \mathrm{~g} \text { PCU }\end{array}$ & $\begin{array}{l}300 \mathrm{~g} \text { thruster }+ \\
1 \mathrm{~kg} \text { PCU }\end{array}$ & $<0.2$ (4 units incl. PCU) & $<0.1$ & $<0.06 \mathrm{~g}$ \\
\hline Power (W) & 0.5 (heater) & 7 (heater) & $1-2$ & $<3$ (valves) & $<1.5$ \\
\hline$I_{\mathrm{sp}}(\mathrm{s})$ & $>5,000$ & $>4,000$ & $>500$ & $290-330$ & 153 \\
\hline Total impulse (Ns) & $>30^{*}$ & $>600^{*}$ & $50-500$ & $>5000$ & $>2000$ \\
\hline $\operatorname{MIB}(\mu \mathrm{Ns})$ & $<5 \times 10^{-3}$ & $<5 \times 10^{-3}$ & $10-30$ & & \\
\hline Thrust & $0.1-15 \mu \mathrm{N}$ & $0.1-300 \mu \mathrm{N}$ & $\sim 10 \mu \mathrm{N}$ & $1-3 \mathrm{~N}$ & $150-900 \mathrm{mN}$ \\
\hline Propellant & Indium & Indium or Gallium & Teflon & $\begin{array}{l}\text { Ethanol, RP-1; } \\
\mathrm{H}_{2} \mathrm{O}_{2}(87.5 \%)\end{array}$ & $\mathrm{H}_{2} \mathrm{O}_{2}(87.5 \%)$ \\
\hline $\begin{array}{l}\text { Feed/operating } \\
\text { Pressure (bar) }\end{array}$ & Self-feeding & Self-feeding & N/A & $6-12$ bar & $3-6$ bar \\
\hline $\begin{array}{l}\text { Flow/consumption } \\
\text { Rate }(\mathrm{g} / \mathrm{s})\end{array}$ & (depends on thrust) & (depends on thrust) & N/A & $0.2-1 \mathrm{~g} / \mathrm{s}$ & $0.1-0.4 \mathrm{~g} / \mathrm{s}$ \\
\hline Pulse rate $(\mathrm{Hz})$ & $>50 \mathrm{~Hz}^{* *}$ & $>50 \mathrm{~Hz}^{* *}$ & $0.5-3$ & TBD & TBD \\
\hline Pulse duration (s) & $* *$ & $* *$ & $\sim 10 \mu \mathrm{s}$ & TBD & TBD \\
\hline Exit diameter & $4-8 \mathrm{~mm}$ & $4-8 \mathrm{~mm}$ & $\sim 5 \times 7 \mathrm{~mm}$ & $15 \mathrm{~mm}$ & $5 \mathrm{~mm}$ \\
\hline $\begin{array}{l}\text { Beam } \\
\text { power-to-thrust ratio } \\
(\mathrm{W} / \mathrm{mN})\end{array}$ & $\approx 50 * * *$ & $\approx 80^{* * *}$ & N/A & N/A & N/A \\
\hline Thrust efficiency & $>50 \%$ & $>50 \%$ & & & \\
\hline $\begin{array}{l}\text { Technology readiness } \\
\text { level (TRL) }\end{array}$ & 6 & 3 & 3 & 3 & 3 \\
\hline
\end{tabular}

* Depends on reservoir size and number of LMISs in cluster.

$* *$ Depends on power supply.

$* * *$ Excluding PCU losses and heater.

Indium was chosen as a propellant due to its high atomic mass, low ionization potential, and good wetting properties. Moreover, it can be handled in atmosphere with no risk, which greatly simplifies testing and also relaxes complex sealing procedures prior to launch. Another significant advantage of indium propellant is the fact that the propellant is solid during launch due to its melting point at $156^{\circ} \mathrm{C}$. The LMIS can, therefore, withstand high vibration loads, which has already been demonstrated during many previous launches in representative environments-such as in the
CLUSTER-II qualification, a vibration level of $30 \mathrm{~g}$ RMS was tested along 20-2,000 Hz.

The ion source consists of a needle or capillary covered or filled with indium, which is heated above indium's melting point $\left(156.6^{\circ} \mathrm{C}\right)$. Then, a sufficiently high electric potential is applied between the emitter and an extractor electrode until a field strength of about $10^{9} \mathrm{~V} / \mathrm{m}$ is reached at the tip. The equilibrium between the surface tension and the electric field strength forms a so-called Taylor cone on the surface with a jet protruding due to space charge (see Figure 2). Atoms 


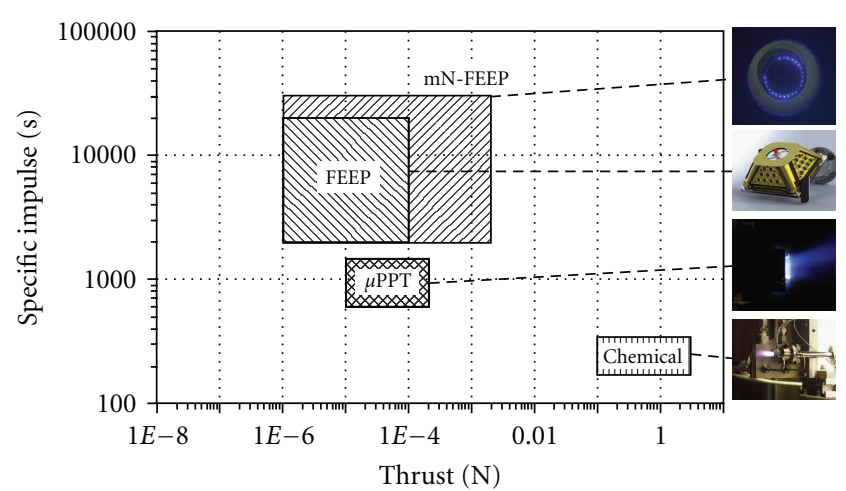

FIGURE 1: Overview of FOTEC microthruster's performance.

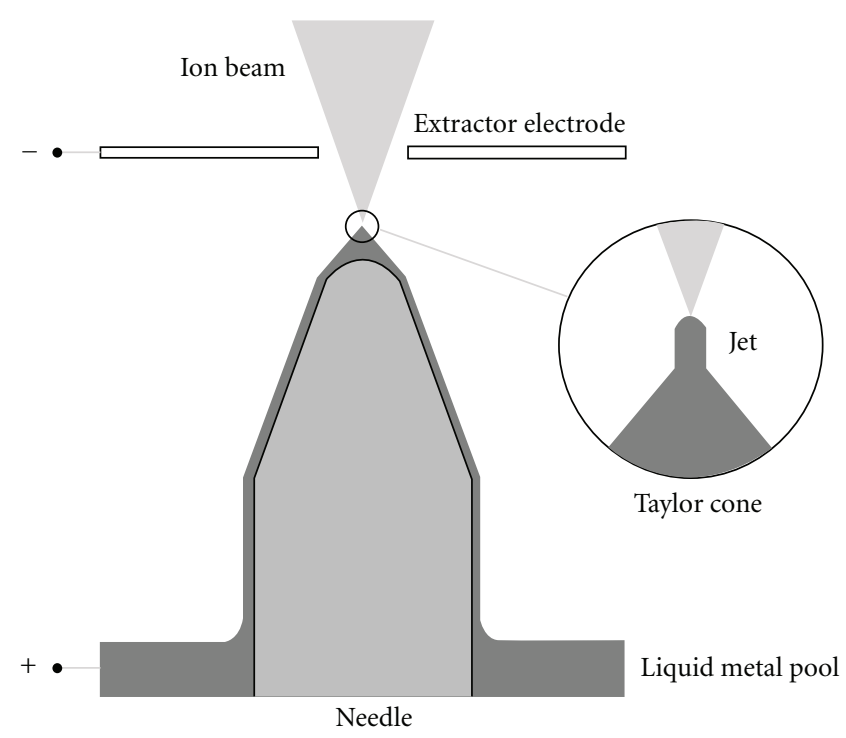

FIgURE 2: Concept of a needle liquid-metal-ion source.

are then ionized at the tip of the jet and accelerated out by the same field that created them. The expelled ions are replenished by the hydrodynamical flow of the liquid metal. Contrary to other electric propulsion systems, ionization and acceleration takes place in one step using the same electric field. This leads to a very high electric efficiency (>95\%). Indium ions are $98 \%$ singly charged along the complete thrust range. Typical emitter voltages range from $3.5-10 \mathrm{kV}$ for currents of $1-150 \mu \mathrm{A}$ of a single LMIS. This corresponds to a thrust of $0.1-15 \mu \mathrm{N}$. Depending on the total impulse that the thruster has to deliver, several different tank reservoirs were developed ranging from $0.22 \mathrm{~g}$ up to $30 \mathrm{~g}$ of indium capacity (see Figure 3 ). The indium flow towards the emission site is enhanced by capillary forces using fins inside the reservoir structure.

Usually, the current emitted by a single LMIS is limited to about $100 \mu \mathrm{A}(\simeq 10 \mu \mathrm{N})$ for long-term operation. Higher currents lead to an excessive generation of droplets which causes very small mass efficiencies as well as erosion of the emitter tip. Lifetime limits due to tip erosion as well as droplet deposition were extensively studied. Dedicated

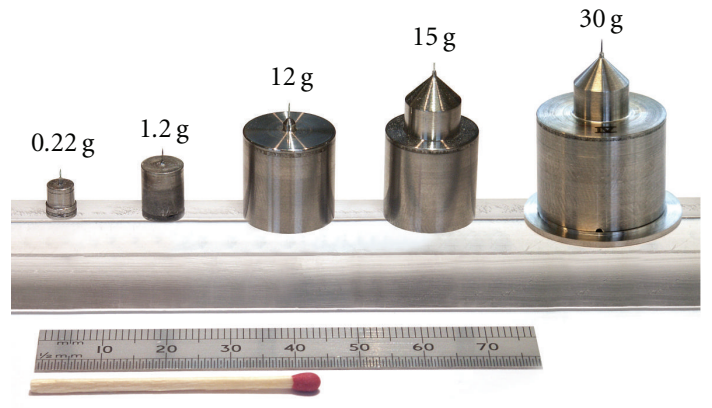

Figure 3: Indium reservoirs.

TABLE 3: Summary of FEEP thruster performance.

\begin{tabular}{lcc}
\hline & Clustered FEEP & Multitip FEEP \\
\hline No. of emitters & $4-16$ & 28 \\
Propellant & In & In or Ga \\
Reservoir weight & $15 \mathrm{~g}$ & $>15 \mathrm{~g}^{*}$ \\
Curr./emitter & $1-150 \mu \mathrm{A}$ & Up to $3 \mathrm{~mA}$ \\
Voltage & $3-7 \mathrm{kV}$ & $7-18 \mathrm{kV}$ \\
Thrust/emitter & $0.1-12 \mu \mathrm{N}$ & $0.1-350 \mu \mathrm{N}$ \\
Thrust noise & $<0.1 \mu \mathrm{N} / \sqrt{\mathrm{Hz}}$ & $<0.1 \mu \mathrm{N} / \sqrt{\mathrm{Hz}}$ \\
Thrust Resolution & $<0.1 \mu \mathrm{N}$ & $<0.1 \mu \mathrm{N}$ \\
$I_{\text {Sp }}{ }^{*}$ & $4,000-6,000 \mathrm{~s}$ & $6,000-8,000 \mathrm{~s}$ \\
Beam power/thrust** & $40-55 \mathrm{~W} / \mathrm{mN}$ & $60-85 \mathrm{~W} / \mathrm{mN}$ \\
Beam divergence & $<25^{\circ}$ & $<25^{\circ}$ \\
Lifetime* & $20,000 \mathrm{~h}$ & $10,000 \mathrm{~h}$ \\
\hline
\end{tabular}

* Can be enlarged to customer specification.

**Varying over the current-voltage characteristic.

lifetime models were developed and verified which enables to predict emitter lifetimes under different operating conditions [4].

To achieve higher thrust, it is necessary to either cluster individual LMIS or to use LMIS with multiemission tips. Both approaches have been pursued. The LMIS clusters are presently at a higher technology-readiness levels (TRLs) due to extensive development and testing especially during the GOCE and LISA pathfinder satellite programs [5-12]. A multiemission tip LMIS based on porous tungsten is presently under development for an mN-FEEP thruster targeting the needs of future Earth observation missions [13]. It enables much smaller designs, thus saving volume and weight. Moreover, it also promises much more rapid production times. A summary between key performance parameters of both designs is summarized in Table 3 .

2.1.1. Clustered-FEEP Thruster. In order to achieve a homogenous operation and to operate a cluster with a single HVpower supply providing a common voltage throughout the cluster, it is necessary to provide LMIS with high electrical impedance. This required the development of special LMIS with very sharp tips as well as the implementation of preresistors. 


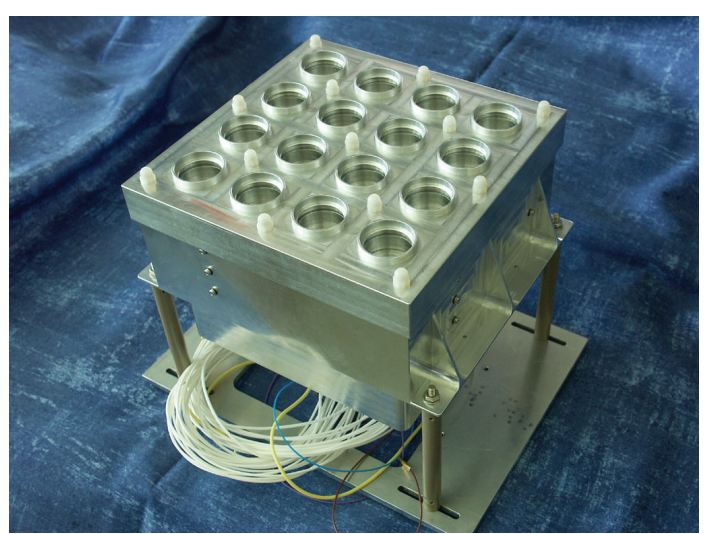

FIgURE 4: Breadboard thruster $(4 \times 4$ LIMS $)$.

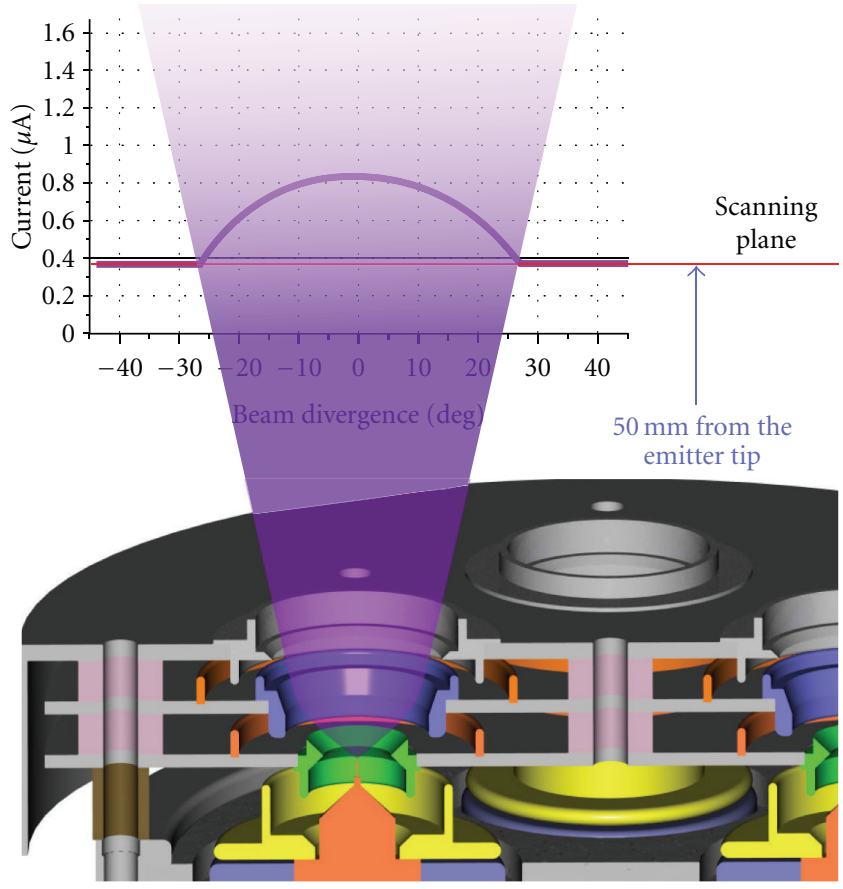

Figure 5: Focusing electrode.

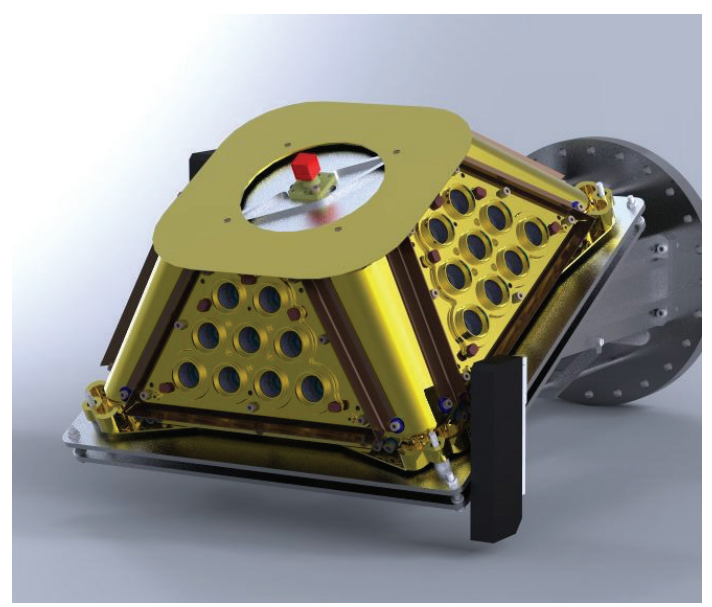

Figure 6: LISA pathfinder in FEEP thruster $(9 \times 4$ LIMS $)$.

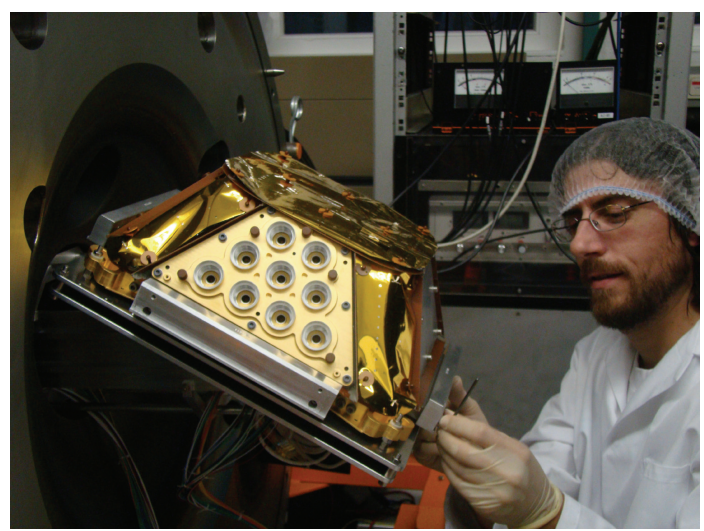

FIGURE 7: LISA pathfinder thruster installed in vacuum chamber.

We manufactured breadboards with clusters up to a size of $4 \times 4$ LMIS for thrust levels up to $200 \mu \mathrm{N}$ as shown in Figure 4 . In addition, focusing electrodes were implemented to achieve a maximum half-angle beam divergence of less than $25^{\circ}$ at maximum thrust (see Figure 5). Recently, a cluster of $2 \times 2$ LMIS were successfully demonstrated in a $5000 \mathrm{~h}$ endurance test [7] running at a thrust level of $25-30 \mu \mathrm{N}$. In this test, it was shown that a single emitter demonstrated $175 \mathrm{Ns}$ (the overall assembly demonstrated $440 \mathrm{Ns}$ ) with a propellant consumption of only 3 grams.

Fotec together with Astrium is presently developing a FEEP thruster for ESA's LISA pathfinder program [12]. This thruster shall provide a thrust level of $0.1-100 \mu \mathrm{N}$ with a cluster of 9 emitters (see Figures 6 and 7). Four thruster positions are integrated into one thruster cluster as shown in Figure 6. An extensive qualification program is currently underway to qualify the indium FEEP thruster technology. In an endurance test lasting over 3650 hours, a total impulse of $586 \mathrm{Ns}$ was collected with a flight representative thruster unit in combination with a flight-representative power supply provided by Galileo Avionica. The thruster has an exceptionally low rate of sparks, and its noise was found to be well below the stringent noise requirements of LISA $(<0.1 \mu \mathrm{N} / \sqrt{(\mathrm{Hz})})$. Based on the performance of the thruster during the 3,650 hours, the expected lifetime of the system was extrapolated to 39,000 hours, which translates into a total impulse of $6,300 \mathrm{Ns}$ at an average thrust of $50 \mu \mathrm{N}$.

The performance values for a single in-FEEP emitter, baselined for cluster operation, is summarized in Table 3.

The in-FEEP thruster is presently under qualification in the LISA pathfinder program targeting a thrust level of $0-$ $100 \mu \mathrm{N}$ with a cluster of 9 emitters.

2.1.2. Multitip FEEP Thruster. In order to further increase the number of emitters and to make the overall module more compact, a new type of high-current ion source was developed based on porous tungsten. There are two basic types of emitter geometries for LMIS: needle- and capillary-based emitters. The needle emitters have usually much larger electrical impedances compared to the capillary emitter which makes them suitable for clustering (as discussed above). 


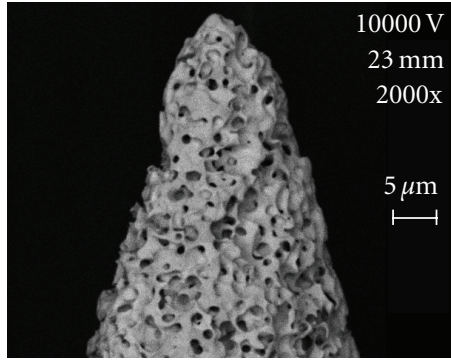

(a)

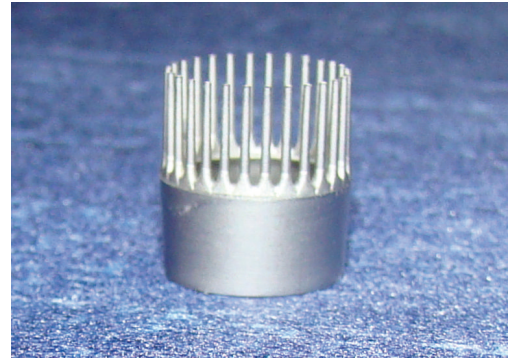

(b)

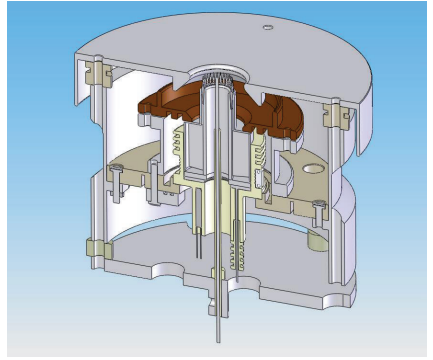

(c)

FIgURE 8: Porous tungsten FEEP thruster: porous tip, crown multitip emitter and thruster design.

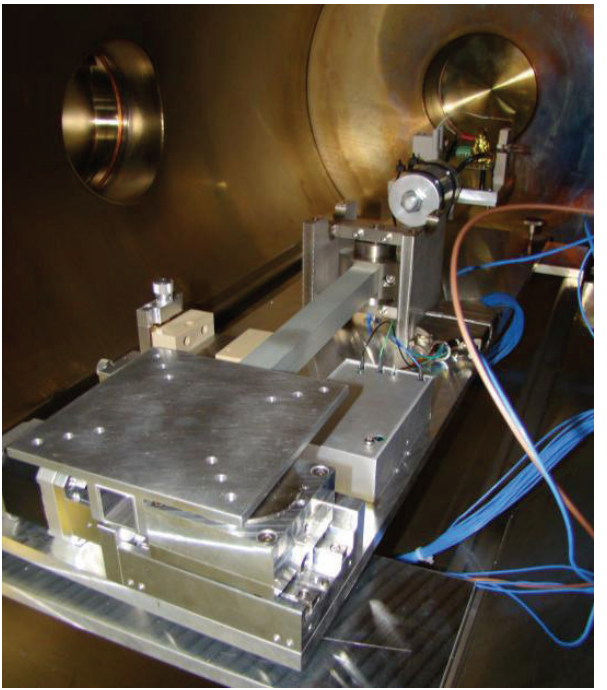

Figure 9: Micro-Newton thrust balance.

However, capillary emitters are usually more stable and reliable - and they can be produced with very similar characteristics. We, therefore, decided to design a multitip emitter using porous tungsten needles in order to combine the advantage of high electrical impedance with excellent stability.

The emitter is manufactured using the micropowder injection moulding technique ( $\mu$-PIM) $[13,14]$. A special feedstock is prepared using tungsten micropowders and the needle structure is formed using dedicated moulding tools. After sintering, the porous emitter structure can be etched similarly to the traditional solid tungsten needle emitters. Currently, $85 \%$ porosity and micron-sized pores can be achieved.

We designed a 28-emitter crown emitter which can produce currents in the range of $3 \mathrm{~mA}$ (corresponding to about $350 \mu \mathrm{N}$ ) as shown in Figure 8. Our test data indicated an exceptional operational stability of the ion source and no measurable change in performance after more than 20 thermal cycles and exposure to oxygen.

This behaviour is attributed to the excellent capillary properties of the porous needle itself. Figure 8 shows the crown-shaped source and the thruster prototype. Presently, the porous LMIS is further optimized for homogeneity throughout all emission sites. This type of LMIS can form the core of future FEEP thrusters that enables high-accuracy attitude and orbit control in combination with a very large thrust range to perform also station-keeping duties in one thruster package.

2.2. Miniaturized Pulsed Plasma Thruster. The trend to microsatellites and even satellites in the $1 \mathrm{~kg}$ range (nanosatellites, e.g., CubeSats) necessitates the development of miniaturized spacecraft components such as the propulsion system. Electric propulsion systems are obviously the first choice for microsatellites due to their much higher specific impulse and the resulting mass savings in comparison to chemical propulsion.

Several electric propulsion systems are under consideration for microsatellites. However, from all these systems, pulsed plasma thrusters (PPTs) are especially amenable to miniaturization. This is due to their structural simplicity, the utilization of solid propellants, and their uniquely low power requirements. The fact that PPTs uses solid propellants is of particular importance. A major contribution to the development time and cost to downscale other systems, which use fluid or gaseous propellants, is devoted to the design of miniaturized subcomponents like pumps and valves. PPTs on the other hand do not include any moving parts (with the exception of a load spring for the propellant feed). This will, therefore, not only keep the development time and cost low but also promise to have a rather constant size to mass ratio when miniaturized.

Various attempts have been conducted to miniaturize pulsed plasma thrusters in the recent years $[15,16]$. A common problem in these efforts was the carbonization of the Teflon surface. This is a well-known problem since the beginning of the PPT research and is mainly due to an incomplete coupling of the electric energy into the propellant surface. Furthermore, miniaturizing a PPT can severely impact the ablation and acceleration mechanism. These changes and their implications are not yet understood but are required to successfully miniaturize PPTs. For example, the increasing ratio of electrode area to plasma volume might promise a more efficient acceleration process (higher ionization) but also increase the potential of losses (frozen flow and viscous boundary layer losses). 


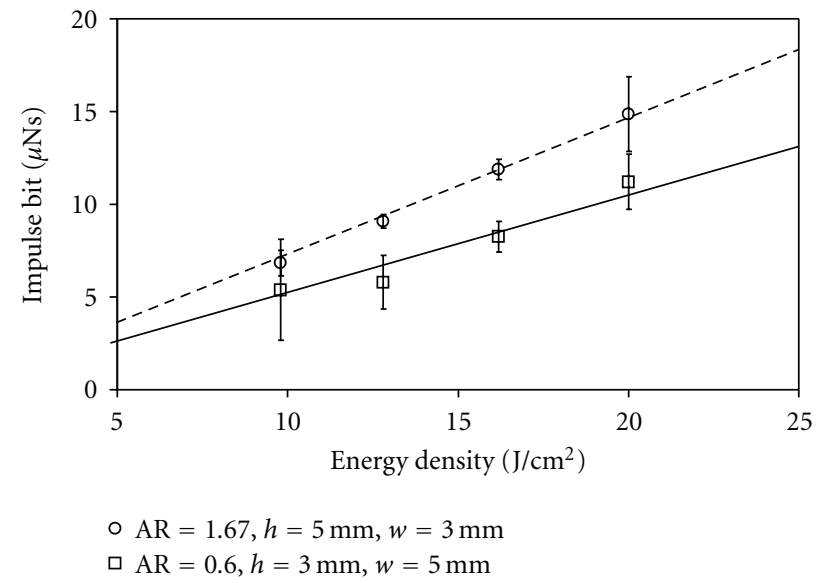

(a)

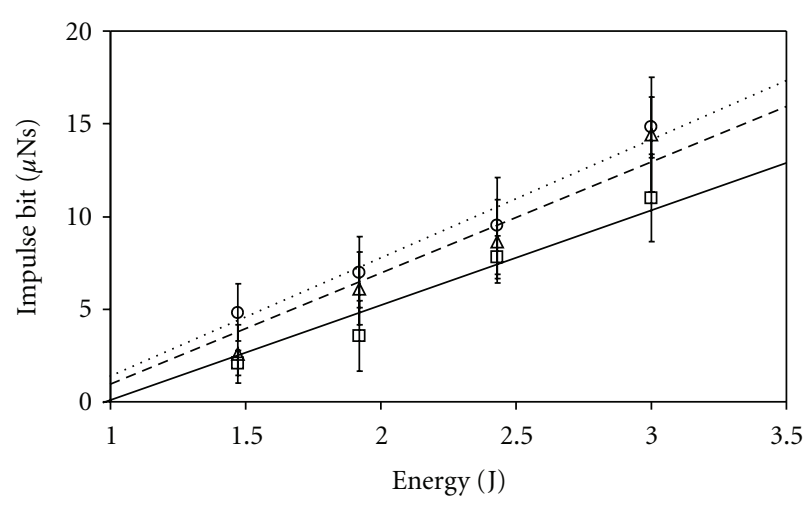

$\triangle$ Average impulse bit, flare half angle $30^{\circ}$

- Average impulse bit, flare half angle $15^{\circ}$

$\square$ Average impulse bit, flare half angle $0^{\circ}$

(b)

FIGURE 10: Experiment evaluation of $\mu$ PPT performance. (a) Varying with energy density at different AR. (b) Varying with energy at different flare half-angle.

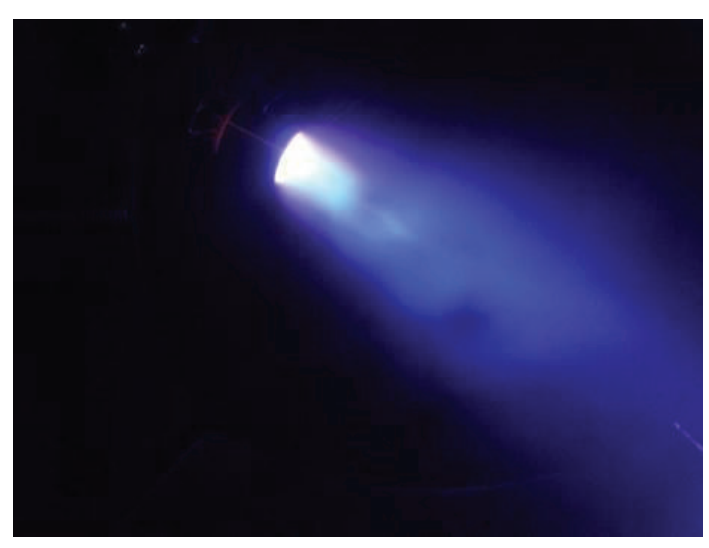

FIGURE 11: Discharge of a $\mu$ PPT during a lifetime testing.

The development of a $\mu \mathrm{PPT}$ at Fotec is, therefore, done in two major steps: (i) by analytically investigating the various changes in the ablation and acceleration processes when changing the PPT geometry (electrode length, width, and shape) and the circuitry (inductance, resistance, and capacitance) and (ii) experimental verification of the results of the analytic model with a dedicated $\mu \mathrm{N}$ thrust balance (see Figure 9). The goal of this effort is the development of a miniaturized $\mu$ PPT capable to use on CubeSats [17]. Obviously, this is a very challenging goal due to the extreme constrains coming along with such an application due to the limitation in volume and power existing on nanosatellites.

An analytical model based on an oscillatory circuit equation and dynamic equation for a uniform plasma slug has been developed in order to provide a design tool which is able to predict the dependence of $\mu \mathrm{PPT}$ performance on electrode configuration and circuit parameters [18]. The results of the model show good agreement with experimental results and have been implemented to improve $\mu \mathrm{PPT}$ performance.

One example of recent experimental investigation is the assessment of the influence of aspect ratio (height over width) and, in case of the rectangular PPT type, of the flare angel on thruster performance [19]. Two examples of the outcome of such tests are depicted in Figure 10.

Further investigations are focusing on a particular problem in the miniaturization of PPTs, namely, the ignition system. Flawed design of the ignition system results in unreliable ignition or premature carbonization of the Teflon surface leading to a total and premature failure of the thrusters. Simple downscaling of ignition systems used in larger systems is not straightforward. Previous efforts to do so resulted in ignition systems not much smaller than the $\mu$ PPT itself and rather short lifetimes of roughly 20,000 ignitions. Recent progress in the development of the ignition system, based on a system of multiple internal electrodes, extended the lifetime of the thruster to more than 300,000 ignitions (see Figure 11). Presently, further improvements are implemented to further increase the lifetime to 500,000 ignitions at constant thrust and with an expected specific impulse of $\sim 500 \mathrm{~s}$. The final $\mu \mathrm{PPT}$ system will consist of a printed circuit board (PCB) including four $\mu$ PPTs energy storage, converters, and ignition electronics.

\section{Green Propellant Chemical Micropropulsion}

Green propellants such as hydrogen peroxide have recently gained much attention. Compared to the presently used propellant combinations such as for example monomethyl hydrazine $(\mathrm{MMH})$ and dinitrogen tetroxide $(\mathrm{MON}-3)$, green propellants have a much lower level of toxicity and have, therefore, the potential to significantly reduce recurring and nonrecurring costs. Not only does this potentially allow the established industry to lower their overall product costs but also it opens up possibilities for emerging companies, research institutes, and even universities since handling highly toxic substances during the development phase was prohibitive both from funding and also from legal point of view. 

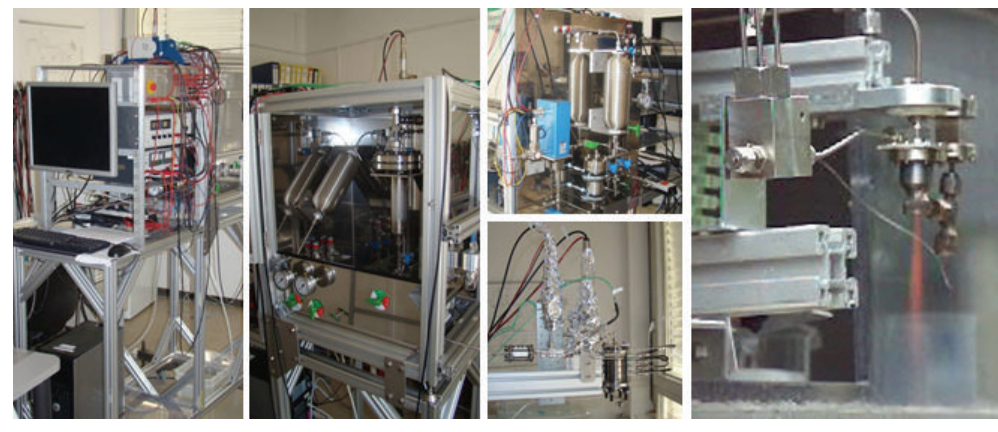

FIGURE 12: Catalyst and ignition assessment facilities.

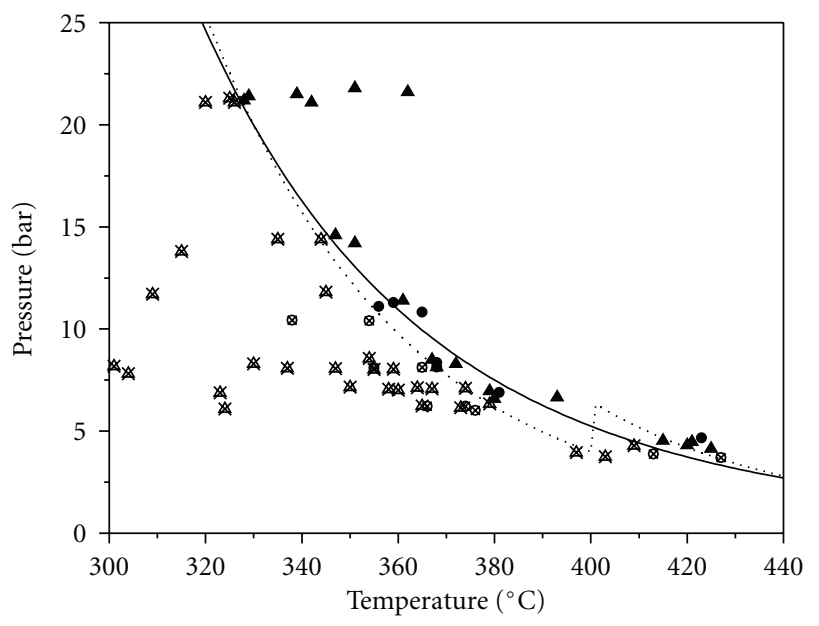

- Yes-ignition $V_{c}=3156 \mathrm{~mm}^{3}$

No-ignition $V_{c}=3156 \mathrm{~mm}^{3}$

- Yes-ignition $V_{c}=1648 \mathrm{~mm}^{3}$

No-ignition $V_{c}=1648 \mathrm{~mm}^{3}$

…. Correlated $P_{0}-T_{0}$ ignition (1st and 2nd condition)

- Correlated $P_{0}-T_{0}$ ignition (2nd condition)

Figure 13: Pressure-temperature autoignition behaviour of Jet A$1 / \mathrm{O}_{2} / \mathrm{H}_{2} \mathrm{O}$.

Since 2005, we were commissioned by the European Space Agency (ESA) to develop a bipropellant and a monopropellant system based on hydrogen peroxide $\left(\mathrm{H}_{2} \mathrm{O}_{2}, 87.5 \%\right.$ by wt). In the framework of this effort, we established a comprehensive chemical propulsion lab. Test facilities to assess various catalysts used for the decomposition of the hydrogen peroxide as well as ignition facilities to assess ignition properties of various fuels in combination with hydrogen peroxide were established (see Figure 12).

3.1. Bipropellant Microrocket Engine. Assessing the suitability of a propellant candidate to be a potential replacement for existing propellants is a complex effort due to the many existing requirements. One of the essential properties for a suitable propellant or propellant combination is the ignitability and ignition delay characteristics. The ignition facility is capable to investigate the ignition properties of a large variety of fuels in combination with hydrogen peroxide. Such

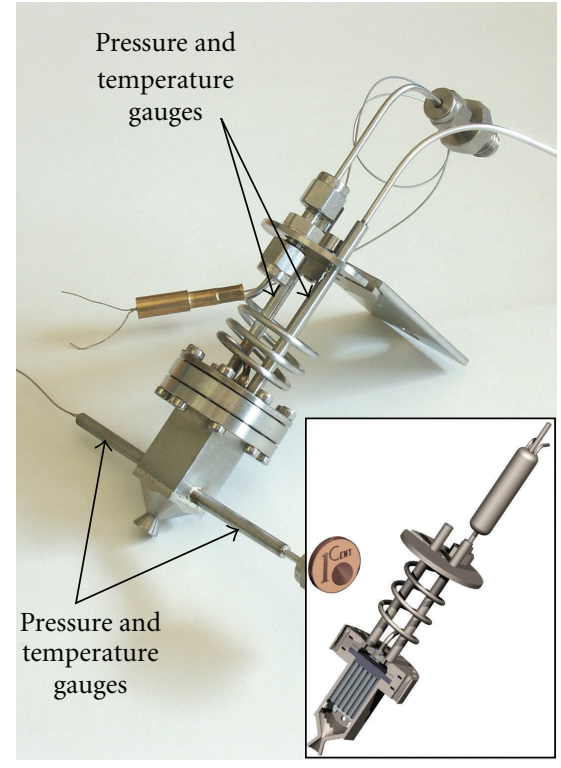

FIGURE 14: Laboratory model of the monopropellant thruster and a cross-section showing the internal assembly with the catalyst.

a propellant combination has the advantage of being quasihypergolic, in other words, it does not require an ignition system. However, the ignitability depends on the combustion chamber geometry, injector type, and pressure/temperature conditions. We are investigating this parameter space with its ignition facility to optimize the ignition characteristic and performance. Figure 13 depicts some of the results for the hydrogen peroxide/kerosene combination [20]. As shown in Figure 13, the ignitability of this propellant combination depends clearly on the temperature-pressure point present in the combustion chamber. Given a certain temperature of the hydrogen peroxide when injected into the combustion chamber, the design (e.g., throat diameter) and operational conditions (e.g., mass flow rates) have to be such that a certain combustion chamber pressure is achieved. This is indicated in Figure 13 by the grey symbols (no ignition), and black symbols (ignition) respectively.

In addition, we are leading the largest European effort with regard to the investigation of green propellants. Within the 7th EU framework program (FP7), The University of Applied Sciences at Wiener Neustadt (previously the Austrian Institute of Technology) is coordinating a consortium 


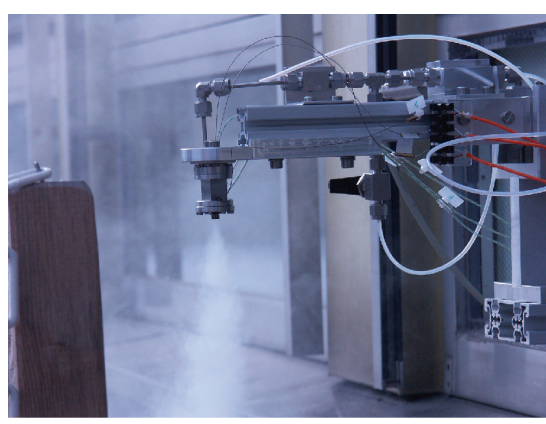

(a)

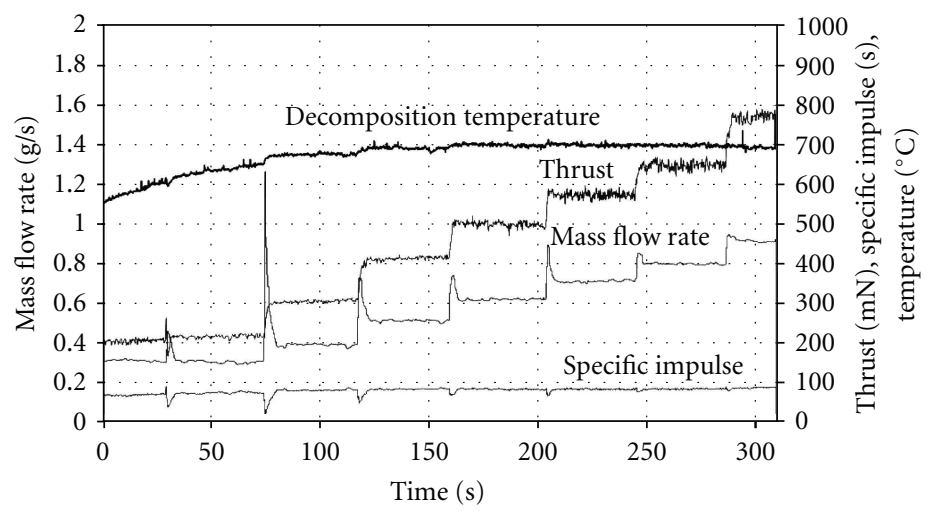

(b)

FIGURE 15: Monopropellant thruster test and direct thrust measurements as a function of the mass flow rate.

consisting of 11 entities from 7 European countries. In this project, named GRASP (green advanced space propellants), more than 100 potential green propellants have been initially assessed. After applying several selection loops, 28 propellants have been identified with the largest potential to be suitable alternatives for presently used toxic propellants. The selection was based on toxicity assessments, general substance properties, predicted performance, as well as on cost and availability $[21,22]$. The initial, mostly theoretical, assessment was then expanded to various experimental assessments. Roughly 45 different experimental facilities are utilized within the GRASP consortium for propellant and catalyst assessments. Based on such tests, a further downselection of propellants has been conducted which are presently tested on propulsion level. The GRASP consortium has designed several different propulsion systems (monoand bipropellant and hybrid) spanning a thrust range between $1 \mathrm{~N}$ to $500 \mathrm{~N}$. All those propulsion system have in common that they use exclusively propellants with toxicity levels significantly lower than those of hydrazine ( $\mathrm{MMH}$ and UDMH), dinitrogen tetroxide (NTO), and so forth. The GRASP project will be concluded in 2012. Until then, it is expected to have experimentally identified several propellants with characteristics and performances similar or better than those presently used. This would provide the respective industry with safer and more cost-efficient alternatives and allow those who embrace this new concept a competitive edge in the future.

3.2. Monopropellant Microrocket Engine. Based on a similar philosophy as the bipropellant thruster, the development of a monopropellant thruster was initiated $[23,24]$. Although a monopropellant thruster delivers less specific impulse than a bipropellant thruster, it offers a lower system complexity. Following the model of Sellers [25], a comparison of the "total system costs" for various propulsion systems such as bipropellant thruster, cold gas thruster, and solid thruster. was performed. This analysis includes propulsion system characteristics such as the necessary propellant mass, the required power, the system price, safety, and risks. This analysis concluded that a monopropellant thruster has significant
TABle 4: Performance parameters of the bipropellant thruster system.

\begin{tabular}{lc}
\hline Thrust & $1-5 \mathrm{~N}$ \\
Specific impulse & $320 \mathrm{~s}$ \\
$\Delta \mathrm{V}$ & $500 \mathrm{~ms}^{-1}$ \\
Maximum dry mass & $400 \mathrm{~g}$ \\
Maximum volume & $0.8 \mathrm{~L}$ \\
Satellite classes & $10-100 \mathrm{~kg}$ \\
\hline
\end{tabular}

TABLE 5: Performance parameters of the monopropellant thruster system.

\begin{tabular}{lc}
\hline Thrust & $100-1,500 \mathrm{mN}$ \\
Specific impulse & $140-180 \mathrm{~s}$ \\
$\Delta \mathrm{V}$ & $50-300 \mathrm{~m} \cdot \mathrm{s}^{-1}$ \\
Mass flow rate & $0.055-0.9 \mathrm{~g} \cdot \mathrm{s}^{-1}$ \\
Lifetime goal & $\sim 16$ hours \\
\hline
\end{tabular}

advantages for certain missions such as remote sensing and experimental space missions requiring a $\Delta V$ between 50 and $300 \mathrm{~m} / \mathrm{s}$ (see Table 4 ).

Encouraged by this analysis, the development of experimental model of a monopropellant thruster was initiated. The envisioned performance parameters is listed in Table 5.

Hydrogen peroxide decomposes not only when in contact with a suitable catalyst but also when exposed to thermal heating. To achieve a highly efficient decomposition of the hydrogen peroxide, it is, therefore, important to study the thermal characteristics of the thruster. A simple thermal model of the thruster was, therefore, established. Several thermocouples are, therefore, included in the design to measure the temperature of the hydrogen peroxide before and after decomposition. This will not only help to evaluate the thermal model but also help to identify the next improved level in the design.

Several laboratory models were designed and tested with various catalysts and different mass flow rates and hydrogen peroxide concentration (75\%-87.5\%) as shown in Figure 14. Figure 15 shows the thruster during a firing test in standard 
atmospheric conditions (1 bar) and depicts the obtained decomposition temperatures, thrust, and specific impulse as a function of the mass flow rate. It shows clearly that the decomposition temperature (and specific impulse) is rather independent of the mass flow that is the efficiency of the thruster is constant over a relative large range of thrust.

For measuring the thruster performance, a thrust balance was designed and manufactured. Preliminary performance evaluation with the laboratory model of the monopropellant thruster, and this thrust balance have been conducted. The measurements have been conducted under atmospheric conditions. Analysis of the results showed that the thruster has a vacuum thrust range capability ranging from 100 to $800 \mathrm{mN}$. The specific vacuum impulse has been evaluated to be equal to $153 \mathrm{~s}$. This first performance evaluation has, therefore, been judged to be very successful. However, exploiting the whole potential of the $87.5 \%$ concentrated hydrogen peroxide, the specific impulse is expected to increase up to $164 \mathrm{~s}$.

\section{Conclusion}

A wide variety of micropropulsion options are already available at Fotec that can be used for nearly all microsatellite programs - as well as an enabling technology for ultra precise attitude and orbit control. FEEP thrusters have been developed providing a very low thrust noise over thrust levels from sub- $\mu \mathrm{N}$ up to the $\mathrm{mN}$ thrust level. Another electric micropropulsion system called $\mu \mathrm{PPT}$ shows a great promise as a CubeSat propulsion system that will enable finepositioning and other maneuvers at low costs. And finally, microchemical propulsion thrusters will enable higher performance for microsatellites as well as lower the costs due to the use of green propellants.

\section{References}

[1] M. Tajmar, C. Scharlemann, A. Genovese, N. Buldrini, W. Steiger, and I. Vasiljevich, "Liquid-metal-ion source development for space propulsion at ARC," Ultramicroscopy, vol. 109, no. 5, pp. 442-446, 2009.

[2] M. Tajmar, A. Genovese, and W. Steiger, "Indium field emission electric propulsion microthruster experimental characterization," Journal of Propulsion and Power, vol. 20, no. 2, pp. 211-218, 2004.

[3] A. Genovese, M. Tajmar, N. Buldrini, and W. Steiger, "2000hour endurance test of indium field emission electric propulsion microthruster cluster," Journal of Propulsion and Power, vol. 20, no. 2, pp. 219-227, 2004.

[4] M. Tajmar, "Development of a lifetime prediction model for indium FEEP thrusters," in Proceedings of the 41st AIAA/ ASME/SAE/ASEE Joint Propulsion Conference and Exhibit, July 2005.

[5] A. Genovese, N. Buldrin, M. Tajmar et al., "Indium FEEP cluster development," in Proceedings of the 41st AIAA/ASME/ SAE/ASEE Joint Propulsion Conference and Exhibit, July 2005.

[6] N. Buldrini, A. Genovese, and M. Tajmar, "In-FEEP cluster for LISA pathfinder," in Proceedings of the International Electric Propulsion Conference (IEPC '05), 2005.
[7] A. Genovese, N. Buldrini, K. Andres, and M. Tajmar, " $5000 \mathrm{~h}$ endurance test of an indium FEEP $2 \times 2$ cluster," in Proceedings of the 42nd AIAA/ASME/SAE/ASEE Joint Propulsion Conference, pp. 5062-5075, July 2006.

[8] C. Scharlemann, A. Genovese, N. Buldrini et al., "Development and test of an indium FEEP micropropulsion subsystem for LISA pathfinder," in Proceedings of the 43rd AIAA/ASME/ SAE/ASEE Joint Propulsion Conference, pp. 2414-2424, July 2007.

[9] A. Genovese, N. Buldrini, R. Schnitzer, M. Tajmar, and C. A. Scharlemann, "3000 hour lifetime test of an indium FEEP cluster for the LISA pathfinder mission," in Proceedings of the International Electric Propulsion Conference (IEPC '07), 2007.

[10] C. A. Scharlemann, A. Genovese, N. Buldrini et al., "Status of the indium FEEP micropropulsion subsystem development for LISA pathfinder," in Proceedings of the International Electric Propulsion Conference (IEPC '07), 2007.

[11] C. A. Scharlemann, A. Genovese, N. Buldrini, R. Schnitzer, and M. Tajmar, "In-FEEP qualification test program for LISA pathfinder," in Proceedings of the AIAA Joint Propulsion Conference, 2008.

[12] C. A. Scharlemann, A. Genovese, R. Schnitzer, N. Buldrini, P. Sattler, and M. Tajmar, "In-FEEP endurance test for LISA PF," in Proceedings of the AIAA Joint Propulsion Conference, 2009.

[13] I. Vasiljevich, M. Tajmar, W. Grienauer et al., "Development of an indium mN-FEEP thruster," in Proceedings of the AIAA Joint Propulsion Conference, 2008.

[14] M. Tajmar, I. Vasiljevich, and W. Grienauer, "High current liquid metal ion source using porous tungsten multiemitters," Ultramicroscopy, vol. 111, no. 1, pp. 1-4, 2010.

[15] F. S. Gulczinski et al., "Micropropulsion research at ARFL," in Proceedings of the AIAA Joint Propulsion Conference, 2000.

[16] D. H. Simon and H. B. Land, "Pulsed plasma thruster for micropropulsion," in Proceedings of the AIAA Joint Propulsion Conference, 2003.

[17] S. J. Pottinger, D. Krejci, and C. A. Scharlemann, "Development of a $\mu \mathrm{PPT}$ for CubeSat applications," in Proceedings of the AIAA Joint Propulsion Conference, 2008.

[18] D. Krejci and C. A. Scharlemann, "Analytic model for the assessment of the electrode configuration of a $\mu$ PPT," in Proceedings of the AIAA Joint Propulsion Conference, 2009.

[19] D. Krejci and B. Seifert, "Miniaturized pulsed plasma thrusters for CubeSats: modelling and direct thrust measurement," in Proceedings of the 61st International Astronautical Congress, Prague, Czech Republic, 2010.

[20] M. Schiebl, D. Krejci, A. Woschnak, F. Winter, M. Lang, and C. Scharlemann, "Modeling and experimental verification of auto-ignition processes for a green bi-propellant thruster," in Proceedings of the 61st International Astronautical Congress, Prague, Czech Republic, 2010.

[21] C. A. Scharlemann, "Green propellants: global assessment of suitability and applicability," in Proceedings of the 3 rd European Conference for Aero-Space Sciences (EUCASS '09), 2009.

[22] C. Scharlemann, "GRASP-a European effort to investigate green propellants for space application," in Space Propulsion 2010, San Sebastian, Spain, May 2010.

[23] C. A. Scharlemann, M. Schiebl, R. Amsüss et al., "Monopropellant thruster development: investigation of decomposition inefficiencies," in Proceedings of the 3rd International Conference on Green Propellants for Space Propulsion, Poitier, France, September 2006. 
[24] C. Scharlemann, M. Schiebl, K. Marhold et al., "Development and test of a miniature hydrogen peroxide monopropellant thruster," in Proceedings of the 42nd AIAA/ASME/SAE/ASEE Joint Propulsion Conference, pp. 2434-2445, July 2006.

[25] J. J. Sellers, Investigation into hybrid rockets and other costeffective propulsion system options for small satellites, Ph.D. thesis, University of Surrey, Surrey, UK, May 1996. 

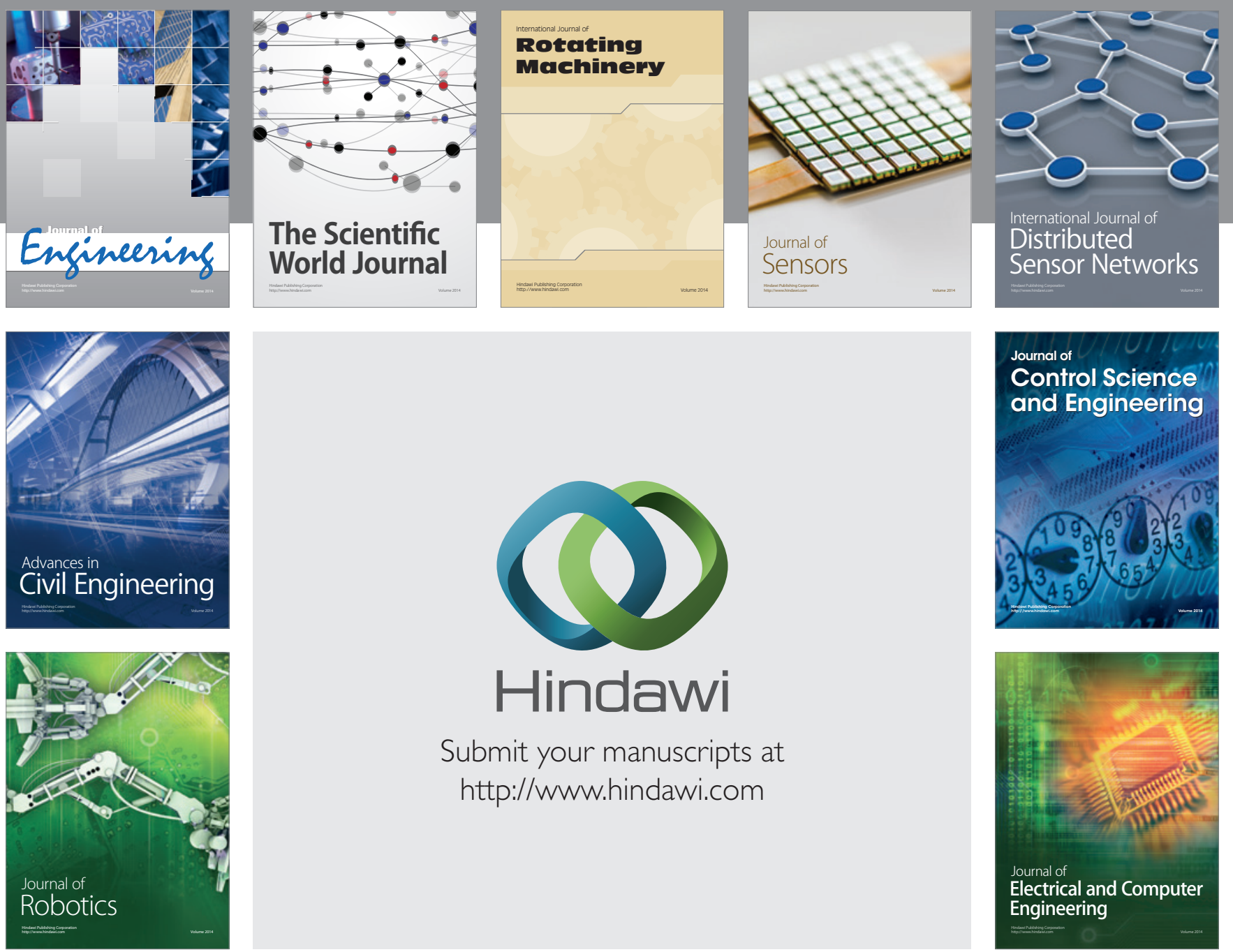

Submit your manuscripts at

http://www.hindawi.com
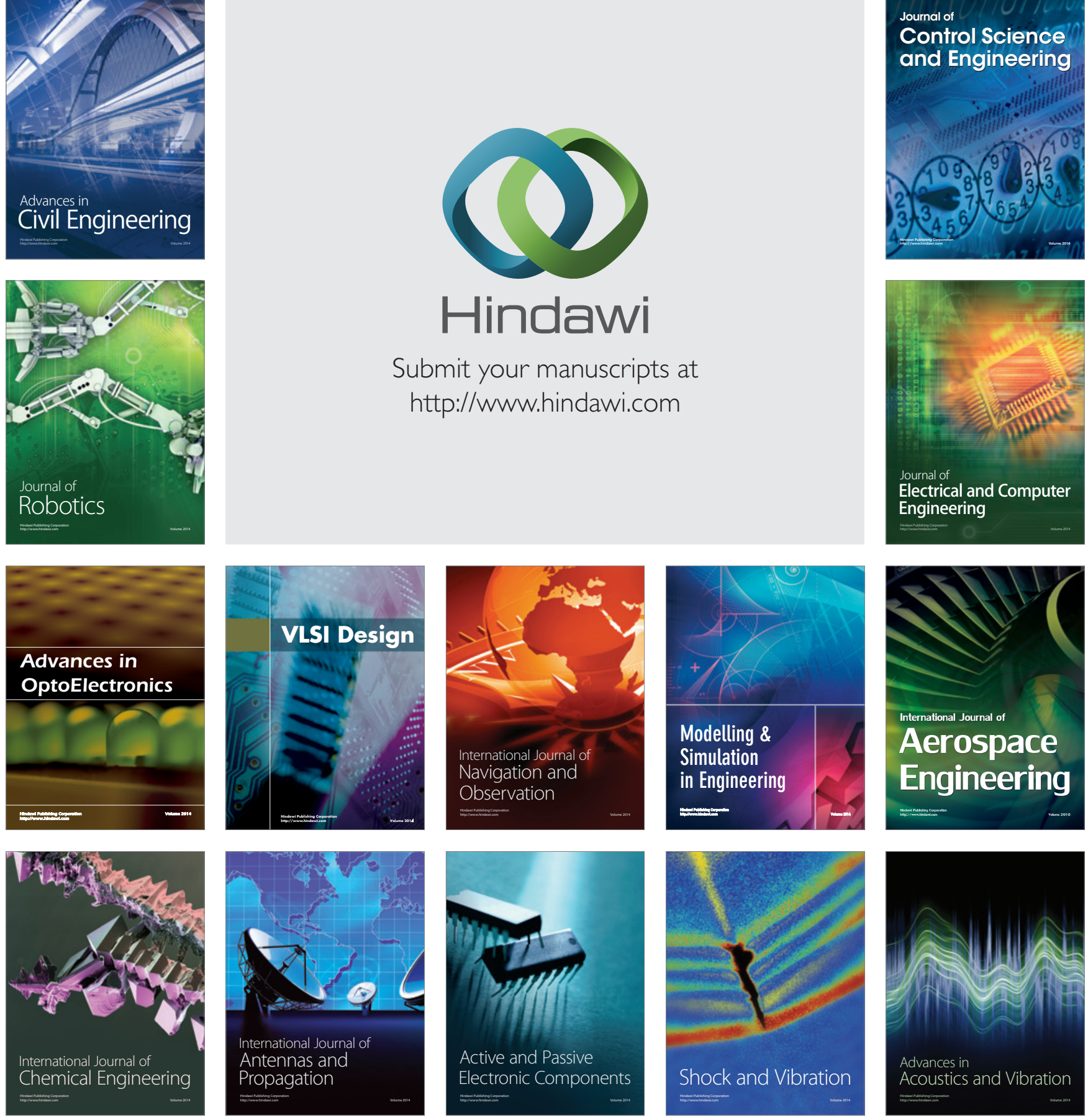